\title{
Edítorial.
}

\section{NEUROLOGICAL THERAPEUTICS.}

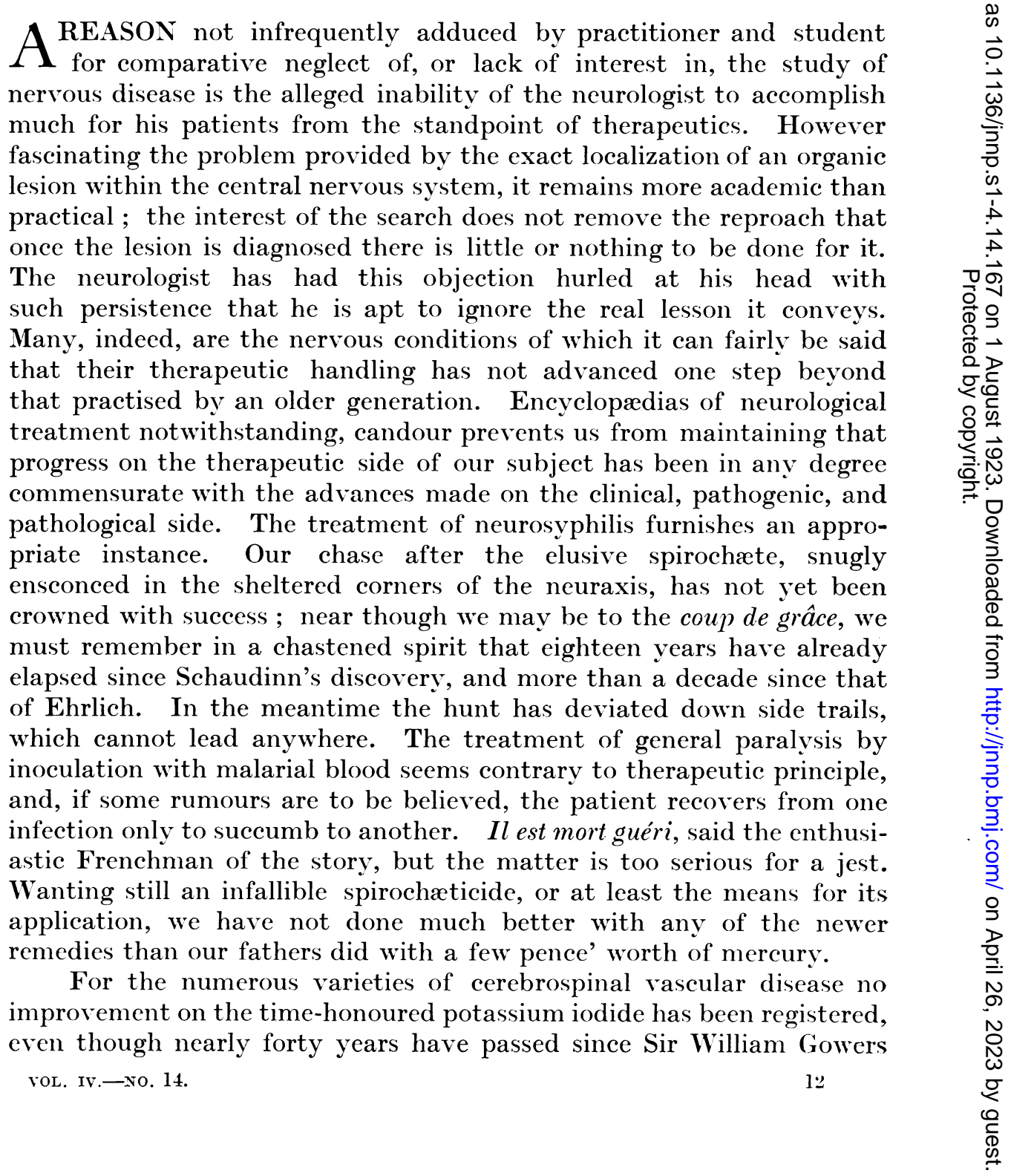


pointed out the disadvantage entailed in its use, viz., its tendency to produce coagulation, especially if exhibited in large doses. Of the different preparations of iodine vaunted in the medical market-place by not disinterested parties, one may fairly say that the more they change the more they remain the same. Another bête noir of the conscientious neurological therapist is the sclerosis of secondary glial proliferation. Shall we ever be able to discover a solvent? Fibrolysin and other remedies of the same type have flattered only to deceive. We do not hear much now of the treatment of syringomyelia and central gliosis by radium or $x$-rays-praiseworthy though seemingly futile attempts to 'do something' for a not uncommon disease, the unfortunate sufferers from which supply ante-mortem clinical problems for budding neurologists and post-mortem material for morbid anatomists, but have nothing to offer the therapeutist. Subacute combined degeneration of the spinal cord still awaits a specific remedy. Its remarkable pathology, with its curious resemblance to that of pellagra, suggests a line of approach from the standpoint of deficiency disease, though some recent efforts at treatment by the administration of vitamins have not proved particularly encouraging. Myasthenia gravis is another affection calculated to damp the ardour of the therapist, while over the myopathies and muscular dystrophies therapeutic helplessness lies like a pall.

In none of these and other nervous maladies that might be referred to, has any therapeutic benefit accrued from the most painstaking pathological investigation, and we may well begin to question the value of the hackneyed contention that morbid anatomy furnishes the key to diagnosis, and so to treatment. It does nothing of the kind. Disease is a process, yet we allow ourselves to be beguiled by end-results. The information garnered by scrutiny of the dead brain and spinal cord is of great value-for the anatomist and morphologist ; it is the reproduction of disease-processes in the experimental animal and their intensive study in life that is calculated to aid treatment. Disseminated sclerosis offers an instance in point. Its cause is no more known to us than it was to Cruveilhier, though its morbid anatomy lies revealed to the last fibre. Neurological dovecotes were fluttered some short time ago by the announcement that a spirochæte had been discovered in that affection, and what if the finding is not, as a fact, substantiated ? At the least it is only through the artificial reproduction of the diseaseprocess by the experimental pathologist that any hope can come. For some nervous diseases, fortunately, he has pointed the way to successful treatment. Epidemics of acute anterior poliomyelitis and of acute cerebrospinal meningitis have come and gone, and we are within measureable distance of specific treatment for the latter, if not, perhaps, for the former. The same cannot yet be said of the affection at present tormenting neurological circles, viz., epidemic encephalitis, although from time 
to time the discovery of its virus is duly announced, only to turn out to have been, in the classic phrase, greatly exaggerated. We may be assured, none the less, that light will eventually come in the way already mentioned, though never by fumbling in the dark among neural cicatrices.

Another large group of nervous maladies presents an even more painful therapeutic problem. What has neurological science been able to accomplish for its cases of Friedreich's disease, its cerebellar atrophies, its familial amaurotics, its Huntingtonians and Parkinsonians, and the whole enormous class of neural degenerations? The problem will not be solved by juggling with nerve tonics, but by the quest of the elixir vitæ. Is this as elusive as it was to the mediæval philosopher? Perhaps the late Dr. Maudsley foresaw a possible solution in a fine passage: "It is not for the most part that brains wear out in old age ; many times they would go on longer if they were properly fed with energy from below, but the organic functions decay and fail ; it is their failure which causes desire to wane and the grasshopper to be a burden ; they are the sources of life's energy and relish, and in their integrity and vigour lies the secret of a fresh and active old age." 